\title{
TEMPO DE INCERTEZAS: ELEMENTOS PARA UMA EDUCAÇÃO EMANCIPATÓRIA NA PERSPECTIVA DA CRÍTICA DE T. W. ADORNO
}

Cleidson de Jesus Rocha(")

\section{INTRODUÇÃO}

O tempo que nos coube viver nos obrigou a deixar as certezas de lado. Em vez delas, se impôs o aleatório, a necessidade da aposta no acaso como experiência válida, numa interrogação sempre permanente sobre o futuro. O sujeito é assim arremessado para dentro de si mesmo, convivendo com constantes perguntas, confrontando-se com todos os medos, entre eles, o pior de todos, o da finitude. Perguntar sobre a natureza, sobre os limites da decadência, sobre o futuro e sobre a impossibilidade da afirmação de uma identidade duradoura que the garanta ser/estar no mundo em condições de transformar o estado de coisas no qual mergulhou o sujeito contemporâneo, são perturbações que delineiam o ser-indivíduo nos tempos presentes.

Esse clima cultural geral em vigor é resultado de um processo em que o tratamento dado ao binômio civilização versus barbárie, de manejo complexo, foi se constituindo, paulatinamente, norteado pelo processo histórico, manifestando-se, em cada tempo e espaço, com feições diferenciadas. Os gregos, por exemplo, reivindicavam para si a alcunha de civilizados, enquanto duvidavam dessa característica nos outros povos, chamados, por diferentes, de bárbaros, por não serem portadores da língua e cultura helênicas. O imperialismo europeu, mais tarde, agiganta as diferenças entre os civilizados e os bárbaros, os povos descobertos e de morada além mar, a quem os civilizados deveriam tutelar em uma missão salvadora, que thes coloca o "fardo civilizador" para tirar os "outros” do atraso, fazendo-os não-bárbaros.

Contudo as variantes do tratamento dessas questões atestam, de qualquer forma, um otimismo nas várias abordagens. Salta dessas posturas a compreensão de que, qualquer que fosse a forma, a civilização seria sempre melhor do que a barbárie. $O$ desenvolvimento histórico do capitalismo, com os avanços da esfera da técnica, da cultura e das formas de produção se acelera tanto que perde o freio. Como consequência, segundo Adorno e Horkheimer (1985), as pretensões

\footnotetext{
(*) Pesquisador colaborador no Programa de Pós-doutorado em Filosofia da Universidade de São Paulo (USP)(20182019); Doutor em Filosofia pela UGF-RJ (2005); Professor adjunto do Centro de Educação e Letras - Campus Floresta, da Universidade Federal do Acre.
} 
de uma vida feliz, porque aparelhada pelo conhecimento, razão e progresso, já não são mais viáveis. O homem, assim, se vê cúmplice da barbárie, por causa dos variados atestados de que a humanidade não soube ou não quis canalizar os benefícios do progresso para formas de bem-estar e de felicidade. Assim sendo se decepciona com os efeitos das guerras, da banalização do mal, enquanto assiste impotente a inúmeros eventos em que a vontade de dominação, a partir da qual o homem se faz "corajoso" até quando se expõe a riscos de vida, ainda está longe de ter um freio.

Num tempo assim, vale lembrar a imagem do homem, elaborada por Freud (1981), como portador de uma sensação de mal-estar, resultante, obviamente, das frustrações de ser contemporâneo de uma mentalidade regressiva e pouco ilustrada, no sentido emancipatório. Para Freud o homem contemporâneo assiste à tendência de que, quanto mais aumente a civilização - em termos de progresso - mais cresça a propensão à barbárie, que é uma regressão no tecido civilizatório e se manifesta aqui e acolá como um sintoma de que nem tudo está tão bem resolvido numa dada sociedade tecnologicamente avançada.

Preocupado em delinear quem seja o sujeito contemporâneo, Adorno realiza os estudos sobre a personalidade autoritária. Estes se dão após o término da elaboração da Dialética do Esclarecimento. Tal estudo é levado à frente com um grupo de cientistas sociais e psicólogos da Universidade de Berkeley. Trata-se de um estudo psicossocial, com base empírica, com aplicação de questionários, testes clínicos projetivos e entrevistas clínicas.

O objetivo do estudo é colaborar para o fortalecimento da democracia americana, evitandose a projeção do fascismo, que se considerava possivelmente latente naquela sociedade. $\mathrm{O}$ que se buscava compreender eram os motivos pelos quais as massas (americanas) puderam aderir a plataformas políticas que contrariavam seus próprios interesses materiais, se submetendo a situações de prejuízos e permanecendo complacentes com estapafúrdios projetos políticos sem se contrapor a eles de nenhuma forma. A base do estudo era a hipótese de que a escolha da ideologia política, longe de ser um processo racional, é largamente determinada por fatores emocionais, ou, melhor dizendo, pela estrutura psíquica dos indivíduos que, por sua vez, é resultado de um processo da estabilização dos mecanismos psicológicos atuantes ao longo da vida do sujeito. Ou seja: partese da hipótese de que há uma estreita relação de mediação entre a esfera do comportamento político, no nível das opiniões, valores e atitudes manifestas do indivíduo e sua estrutura de personalidade. 
Adorno, em entrevista à revista alemã Der Spiegel ${ }^{1}$ (2004) assevera que existe, inerente às massas, o contágio pelo clima cultural geral que esvazia as possibilidades do exercício do convívio solidário, o que faz com que, estas, mesmo quando defendam posições progressistas, sejam niilistas - mantendo-se, assim, conservadoras. Quando delas abrem mão, se rebelando pela defesa de posições mais pessoais, fazem-se fascistas. Esse quadro aponta para a situação na qual os indivíduos, mesmo os não-autoritários, estão sujeitos a um clima cultural geral em que vigora a estereotipia, que é uma tendência a perceber o mundo conforme modelos pré-determinados, estereotipados. Os indivíduos, assim, conseguem somente uma identificação entre pensamento e realidade, numa perfeita sintonia entre o sujeito e o objeto. Esse quadro, contudo, contribui para a glorificação da lógica do capitalismo tardio, em que tudo conspira para reduzir a autonomia do sujeito. Avizinha-se, assim, o pior dos males. Embora o comportamento tipicamente previsível, estereotipado, não possa ainda ser classificado como bárbaro, ele abre caminho para a barbárie.

Não podemos perder de vista que a manifestação de Adorno acima descrita diz respeito a um contexto específico, aquele em que vigorou a sobreposição dos caprichos nazistas, que conspiram contra as possibilidades emancipatórias, impondo em seu lugar, o medo da aniquilação. Mesmo assim, este processo equipara-se ao da separação entre a natureza interna e a natureza externa no ser humano, resultando num conflito de identidade como veremos a seguir.

Para Jeanne-Marie Gagnebin (1997), a separação que acontece entre a natureza interna e a natureza externa do homem repercute de modo substancial tanto no comportamento mimético do sujeito quanto na noção de corpo e de sentidos. De acordo com esta autora, o processo de formação do sujeito se encerrou na repressão da mimesis primeira, originária, que se transformou numa mimesis segunda, perversa. O momento mimético presente na relação do homem primitivo com a natureza expressava o princípio básico do mito, o antropomorfismo, a projeção na natureza do subjetivo. O sobrenatural, espírito, demônios, são imagens espelhadas dos homens “[...] assustados pelos fenômenos naturais" (MATOS, 1989, p. 153).

A experiência de mimetizar a força ameaçadora ocorria pelo medo da aniquilação. Assim como determinados animais possuem caracteres que os confundem ao meio ambiente, livrando-os do ataque de seus predadores e permitindo-lhes a sobrevivência, o homem, num impulso mimético, se assemelhava ao inimigo para escapar do perigo da destruição. Neste impulso de sobrevivência, contudo, ele tinha sua identidade perdida, na medida em que extrapolava os limites que o

\footnotetext{
1 Entrevista concedida por Adorno à revista alemã Der Spiegel, em agosto de 1969. Disponível em: <http://www.scielo.br/scielo.php〉. Acesso em: 22 nov. 2004.
} 
caracterizavam como diferente. Era uma mimesis constituída pelo medo daquilo que mostrava toda sua força: a vida selvagem, as intempéries, a falta de alimento, e ainda, aspectos geográficos.

No desenvolvimento histórico da civilização, o comportamento mimético se transformou devido às novas relações do mundo burguês, pautadas no interesse de eliminar aquilo que se apresenta como dissonante. Esta parece ter sido a proposta do Iluminismo, que prometeu desencantar o mundo dos mitos, através do desenvolvimento da razão científica.

Deste modo, o homem contemporâneo tornou-se vítima daquilo que ele mesmo provocou através de sua pretensão em dominar as coisas do mundo; regrediu em sua capacidade de ouvir e olhar a natureza como um todo repleto de mistérios nunca conhecidos plenamente. $\mathrm{O}$ homem esclarecido passa, então, a olhar a natureza com os olhos do dominador, prestes a explorar e dominar o mundo desconhecido. A fúria desse homem que acredita dominar ocorre, segundo Adorno e Horkheimer, porque mesmo sob a égide da dominação da natureza e, consequentemente, das relações humanas, não se pode dominar completamente o impulso mimético. Instala-se, dessa maneira, o espírito da barbárie, que é a regressão da humanidade. Esta regressão reflete, então, a formação do homem, que, embora seja capaz de produzir bens culturais grandiosos, é, porém, incapaz de reconhecer a grandiosidade das coisas humanas. Adorno explica bem esta contradição quando diz que, mesmo aquelas pessoas dedicadas aos bens culturais se encarregaram tranquilamente da práxis assassina do nacional-socialismo. Isso para ele demonstra a dissociação entre os bens culturais (a cultura) e as coisas humanas, isto é, a consciência, o pensar e o sentir humanos. A contradição desencadeada a partir do processo de apropriação da cultura e da técnica encaminha os homens para a realização da barbárie.

Segundo Adorno (1995a:127), o comportamento bárbaro se aninhou, no que diz respeito ao nazi-fascismo, nos seguintes procedimentos: a) identificação do sujeito com o modelo estereotipado de comportamento social ("identificação cega com o coletivo"); b) o indivíduo imitando o seu líder (político), no sentido da manipulação das massas e dos coletivos.

No livro que no Brasil foi traduzido como Dialética do Esclarecimento (1985) Adorno e Horkheimer discutem que a civilização, em sua ânsia de extinguir a barbárie, acabou aumentando-a a volumes indescritíveis, até o ponto de extinguir as capacidades de racionalização crítica, criando meios para que em seu lugar vigore uma mentalidade administrada, que em tudo se iguala à própria sociedade (corroída e desprovida de saída), construindo mecanismos de dominação cada vez mais eficazes, com vistas à dominação sistemática dos grupos. 
Além disso, hoje em dia se impõe a tendência de que, a partir da preponderância dos meios de comunicação de massa, se fixe o hábito apenas da observação virtual dos objetos, em vez do contato efetivo com estes. Ou seja: à medida em que o acesso à mensagem, às imagens, encontra-se facilitado pelos meios de comunicação (Internet, entre eles), mais se experimenta a satisfação do gosto efềmero do contato virtual com o que é produzido pela indústria cultural, sedimentando-se essa forma de cultura.

\section{FUNÇÕES IMPERATIVAS DA EDUCAÇÃO PARA A AUTONOMIA DEMOCRÁTICA}

As questões relativas à promoção da cidadania e da democracia estão no cerne dos debates sobre emancipação do homem, redefinindo discursos acadêmicos e políticos e afetando também as decisões e ações práticas daqueles que lidam com o processo formativo. Nesse sentido, renovam-se os focos de interesse das preocupações com questões emancipatórias. No plano pedagógico, por exemplo, questões como a relação entre currículo e estrutura social, currículo e cultura, currículo e poder, currículo e ideologia, currículo e controle social são discutidos em artigos e livros e passam a integrar o cerne de um debate que quer ocupar também a prática daqueles que constroem o processo ensino-aprendizagem (MOREIRA; SILVA, 1995, p. 16). Além das questões curriculares, outras tantas compõem o espectro amplo das preocupações educacionais.

A questão da "ideologia", por exemplo, tem sido, desde o início da teorização crítica em educação um dos conceitos centrais a orientar não só a análise do quadro social amplo, mas também envereda pelo setor educacional, orientando posturas e inserções no processo educacional. Para Antônio Flávio Barbosa Moreira e Tomaz Tadeu da Silva (ibid., p. 21), Louis Althusser, com o ensaio A Ideologia e os Aparelhos Ideológicos de Estado, introduz no campo educacional a preocupação com a questão da ideologia em educação, rompendo, assim, a noção liberal e tradicional de educação como desinteressadamente preocupada com a transmissão de conhecimentos. Seu ensaio salienta que a educação constituiria um dos principais instrumentos pelo qual a classe dominante imprimiria suas ideias e garantiria a reprodução das relações de produção de tipo capitalista. A escola funcionaria, para Althusser, como local de reprodução de um conhecimento falso, que só interessava à classe dominante.

A compreensão de que a ideologia se corporificava predominantemente em ideias foi sendo diluída e em vez desta visão passou-se a ver a ideologia como envolvida em práticas materiais, ou seja, implícita em rituais e dispositivos materiais como arranjos espaciais (ibid., p. 25). Ideologia, cultura e poder são, assim, conceitos centrais da teorização crítica. Estendendo e ampliando o 
alcance desses conceitos, tem-se destacado várias outras questões e temas, como currículo oculto, as novas tecnologias e a informática e as novas formas de conceber o conhecimento e a linguagem.

Adorno, embora não manifesta pretender elaborar em termos definitivos um projeto acabado de educação, indica, de forma clara, os elementos indispensáveis para uma educação que vise preparar a humanidade para a não repetição de Auschwitz. Essa recomendação se dá pelo fato de que, para Adorno, o principal papel da educação é trabalhar no sentido de evitar a repetição das atrocidades dos campos de concentração, estes eivados de todos os sentidos negativos da experiência humana. Assim, o conhecimento dos mecanismos que geraram mentalidades capazes de produzir tal horror, precisa ser tomado pela educação como tarefa primordial.

A emancipação, grande meta do projeto da teoria crítica de T. W. Adorno, não pode ser uma dádiva, mas sempre uma conquista. Sendo assim, pressupõe instrumentos de luta. O primeiro deles é a tomada de consciência do desacordo entre consciência e realidade, ou seja, uma posição de desconfiança frente ao real como verdadeiro. O processo de conquista da emancipação é, por isso, momento de equilibrio entre violência e liberdade. O enfrentamento dos esquemas fechados do real, a coragem civil de contraposição às falsas verdades disseminadas como válidas exige a habilidade de enfrentar as ambiguidades do processo de adaptação/emancipação.

A opção que a sociedade atual fez de tomar a violência como fato social comum provoca um estado de espírito imune à sensibilidade. A morte se banaliza e a experiência das "perdas" já não provoca sofrimento. Assim, sem dor, o homem assiste a um atar e afrouxar dos laços sociais sem esboçar resistências, sem lutar pelo reatamento das pontas das "constelações". O desprestígio da experiência corresponde à experiência da morte, já que o nível de impotência que decorre destas situações é equivalente à paralisação fatal dos instintos vitais. Para Batista,

Não se pode negar simplesmente as conquistas humanas no sentido biológico e sociocultural, entretanto erigir-lhes um altar no sentido da naturalização e sacralização de seus procedimentos é afirmar a barbárie até então inerente à civilização. Morte aos mitos, repressão ao medo foram e continuam sendo artimanhas da razão enquanto órgão de adaptação humana. Mas, ao banir o pensamento, a razão tem fracassado no intuito de construir o sujeito, e velhos mitos com novas roupagens ressurgem. A trajetória do pensamento quer nos convencer de uma linearidade e um progresso no mínimo suspeitos. A razão que possibilitou a sujeição da natureza viu-se também confinada às grades que forjou na luta pela autoconservação. A cultura, espaço histórico da constituição do indivíduo, converteu-se em natureza. (ibid., p. 201). 
Um clima assim realiza a conformação da cultura à vida, fazendo com que aquilo a que chamamos formação se congele em categoriais fixas, cada uma delas isolada, podando o sentido mesmo da cultura e promovendo uma formação regressiva. O trabalho de formação pressupõe a tomada de consciência sobre os esquemas de violência hoje instaurados como naturais entre nós, e, principalmente, proteger a humanidade dos perigos de reincidência na barbárie uma vez já cometida contra a humanidade e que ainda se encontra em condições de novas reatualizações.

Por esse motivo, Adorno discorre apropriadamente sobre algumas possibilidades de conscientização dos mecanismos subjetivos que produziram Auschwitz - a mais atroz experiência da banalização do mal -, pois acredita que é preciso reconhecer os mecanismos que tornam as pessoas capazes de cometer tais atos, e que se faz urgente revelar tais mecanismos a elas próprias, procurando impedir que incidam novamente na repetição da extrema barbárie, na medida em que se desperta uma consciência geral desses mecanismos. Ciente de que a educação possa constituir-se como veículo de construção de uma mentalidade autônoma, embora observe que o colapso do sistema e dos métodos educativos não se resolve simplesmente com reformas pedagógicas, Adorno propõe:

(A) Uma educação para a autonomia, uma vez que a "educação tem sentido unicamente se for dirigida à formação de uma autorreflexão crítica", (ADORNO, 1995a:121) através da qual se construa o poder para a reflexão, a autodeterminação, a nãoparticipação;

(B) Promover "uma educação que não premie a dor e a capacidade de suportá-la, [...] e que permita o medo como um aspecto da condição humana, pois quando nos permitirmos ter realmente tanto medo quanto a realidade exige, desaparecerá grande parte dos efeitos deletérios do medo inconsciente e reprimido" (p. 129);

(C) Faz-se necessário também que se esclareça quanto à possibilidade de haver um outro direcionamento para a fúria ocorrida em Auschwitz, quem sabe dirigida a outros grupos;

(D) E, finalmente, diz Adorno, "o centro de toda educação política deveria ser que Auschwitz não se repita. Isso só será possível na medida em que ela se ocupe da mais importante das questões sem receio de contrariar quaisquer potências" (ADORNO, 1995a, p. 137). Para isso, seria necessário que se informasse acerca do jogo de forças políticas localizado por trás da superfície das formas políticas. 


\section{EDUCAÇÃO CONTRA A BARBÁRIE}

A proposta de Adorno, de uma educação contra a barbárie, capaz de evitar a repetição de Auschwitz, não é outra senão aquela capaz de fazer com que se elimine da esfera da cultura toda forma de violência. Assim, diz Adorno:

[...] que o último adolescente do campo se envergonhe quando, por exemplo, agride um colega com rudeza ou se comporta de um modo brutal com uma moça; quero que por meio do sistema educacional as pessoas comecem a ser inteiramente tomadas pela aversão à violência física (p. 165).

Obviamente que todas essas sugestões de Adorno, se aplicadas, não garantem o seu êxito, nem ele próprio seria ingênuo a esse ponto. Chegamos ao nó da questão, pois aqui, no nosso modo de ver, Adorno se emaranha na sua própria complexa teia discursiva, pois ao projetar um certo tipo de possibilidade comportamental pós-Auschwitz, percebemos claramente que nada nos garante que ele possa ir além das projeções. Aqui é relevante notar o contexto em que ele desenha o seu perfil educacional. Nós que vivemos uma era pós-tudo, ao olharmos para trás, notamos que é justamente no irremediável que encontraremos a originalidade do pensamento de Adorno sobre o impasse educacional pós-Auschwitz. Nesse sentido, diante do abismo que se abria para ele e o seu tempo, percebemos a força de um discurso que não se contenta com o seu próprio limite, mas que, na passagem das décadas posteriores, investirá decisivamente nas próprias contradições entre o ser e o não-ser. Ou seja, mesmo diante de algumas inconciliações, ao contrário do que se poderia supor, o processo crítico em que ele se debate agudizará a imagem de uma sociedade que não se contenta nem com suas próprias projeções idealizadas. Por isso, o discurso adorniano para a emancipação só é crível a partir do abismo que a sua própria época lhe proporcionou.

O engajamento de Adorno no combate a toda forma de violência, embora desenhado de forma clara em seu arcabouço teórico, em alguns momentos específicos se manifestou em sua vida prática, exigindo do homem-professor-teórico posicionamento firme em seu combate. Em agosto de 1969, por exemplo, Adorno teve que enfrentar, como professor, um protesto barulhento de um grupo de alunos que lutava pela reforma universitária. Estes alunos chegaram a invadir as salas de aula e exigiam que Adorno tomasse uma posição prática de adesão à luta do movimento estudantil. Esse fato é relatado por Adorno em uma entrevista à revista alemã Der Spiegel, pois se constituiu como um episódio marcante de sua carreira docente, e oportunidade a partir da qual ele discute longamente sobre a relação teoria e prática. Adorno, que afirma não ter sofrido violência física nessa ocasião, considera igualmente violento o fato de os alunos terem feito tanto barulho que a aula se tornou impraticável, deixando claro que aquela era uma ação planejada. Segundo afirma 
Adorno, embora ele tivesse elaborado um modelo teórico de intervenção, jamais imaginou que "as pessoas quisessem realizá-lo com bombas" (ADORNO, 2003:2). Para Adorno, seus escritos não são portadores de nenhum modelo para quaisquer condutas ou quaisquer ações. Segundo ele mesmo afirma, é

[...] um homem teórico, que sente o pensamento teórico como extremamente próximo de suas intenções artísticas. Não foi agora que eu me afastei da prática, meu pensamento sempre esteve numa relação muito indireta com a prática. Talvez ele tenha tido efeitos práticos em consequência de alguns temas terem penetrado na consciência, mas nunca eu disse algo que se dirigisse diretamente a ações práticas (p. 2).

Apesar da recusa da prática, apresentada no parágrafo acima, a teoria crítica sempre deixou claro que pretendia modificar as condições sociais para patamares diferentes das que se encontram. Respondendo às críticas daqueles que lhe cobravam uma adesão ao movimento estudantil, o frankfurtiano assim responde:

Nas organizações estudantis de esquerda, [...] defronto-me sempre com a exigência de entregar-me, de ir junto, e a isso eu venho resistindo desde muito jovem. E nisso nada se modificou em mim. Tento exprimir aquilo que reconheço e sinto. Mas não posso acomodá-lo ao que se fará disso e ao que disso resultará (p. 3).

Esse posicionamento faz emergir a clara convicção de Adorno, que perpassa seus ensinamentos desde a Dialética do Esclarecimento, de que "uma teoria é muito mais capaz de ter consequências práticas em virtude da sua própria objetividade do que quando se submete de antemão à prática”, pois “[...] o relacionamento infeliz entre teoria e prática consiste hoje precisamente em que a teoria se vê submetida a uma pré-censura prática” (p. 3). Isso faz com que os movimentos de esquerda tenham em geral força para arrebanhar fiéis. Contudo, Adorno insiste em que esses grupos não podem invocar modelos de ação que tivessem brotado dos seus ensinamentos. Seria redução de seus trabalhos valorizar as chamadas "ações isoladas", já que não há sentido nestas, uma vez que a grande ênfase dada em suas obras é a da "totalidade social".

\section{CONSIDERAÇÕES FINAIS}

O quadro geral até aqui apresentado dá conta, inicialmente, de esboçar o cenário cinza da cultura contemporânea, segundo a abordagem de Theodor W. Adorno. Contudo, ao tempo em que a indústria cultural cumpre a função de promover a dominação dos grupos por meio da lógica da validade das aparências, alavanca a abertura para questões importantes, que, embora já bastante discutidas, cabem ainda no debate filosófico, especialmente em função da extrema necessidade de 
saídas que todos sentimos nas diferentes esferas da vida, saídas essas que se veem embaraçadas na falta de perspectivas alentadoras para o fazer cotidiano, para nossas atuações profissionais, e no plano científico, que alimentem um pensamento capaz de nos permitir compreender o momento presente e que corresponda ao preenchimento das carências que a epistemologia precisa produzir.

Apesar desse quadro sombrio, sabemos que toda a situação que gerou essa tônica é histórica e, portanto, socialmente produzida. E, assim sendo, ainda que os recursos de reação contra esse quadro ainda não tenham manifestado força suficiente para inibi-lo, compete à vontade humana a criação das condições para tal. Pois a sujeição dos homens à dominação sistemática promovida pela indústria cultural, que é sustentada subjetivamente, gera um quadro de subjugação, que só pode ser voluntário, na medida em que os homens se contrapõem à mudança. Nesse sentido, faz-se necessário o desvelamento dos mecanismos que fazem com que os homens alimentem uma preferência pela manutenção do status quo.

No cerne das reflexões que tentam explicar os mecanismos castradores da autonomia, a posição de Adorno se faz central, já que para ele a indústria cultural, que "atrofia a imaginação e a espontaneidade do consumidor cultural” (1985, p. 119), é sempre um referencial importante. Segundo Martin Jay (1988a, p. 43), leitor de Adorno, a Indústria Cultural investe na destruição da crítica. É, portanto, predisposta à reafirmação da sociedade em seu molde atual, destituído de crítica. A tônica que constitui a subjetividade contemporânea é a lógica da dialética racionalidade $\mathrm{x}$ irracionalidade, quer dizer, existe uma organização racional constituidora de padrões e meios de divulgação do produto cultural, que, enquanto age, esvazia as possibilidades emancipatórias e críticas dos sujeitos. Esta "racionalidade" equivale aos propósitos da indústria cultural que visa imprimir um clima cultural geral de irracionalidade.

Para nós, a posição de Adorno entre teoria e prática imprime ainda mais o selo da condição abissal em que ele produziu a sua obra, com direito a todas as contradições permissíveis que um pensador, a partir da sua generosidade e grandeza intelectual, poderia propor. Nesse sentido, tudo se resolve basicamente nas práticas discursivas de um tempo que the provocou todas as ações de pensamento possíveis. Não estamos falando de vários Adornos, mas de um que soube elaborar o seu pensamento a partir de uma condição intelectual legítima de se lançar no meio do turbilhão e daí tentar tirar os resultados sem que isso progredisse numa determinada posição estática. O seu pensamento, portanto, é o de confronto permanente, mesmo diante de pretensos aliados.

Resumindo, verificamos que Adorno parte da crítica à visão romântica do gênio individual como matéria prima do processo educativo. Ao mesmo tempo, critica a educação massificadora, de 
caráter totalitário, que trabalha com um ideal de bem comum que "paira" acima dos indivíduos. O frankfurtiano identifica no ideal de emancipação, qual seja, a liberação das aptidões intelectuais e morais do indivíduo para o exercício responsável de sua liberdade, condição sine qua non para uma via efetivamente racional de conduzir as relações humanas. Como tal, Adorno vê na emancipação um princípio fundamental para nortear toda ação educativa. Defende, nesse sentido, uma educação para a emancipação baseada em certos princípios básicos tais como: 1) Eleger como principal adversário não a ignorância, mas a barbárie, isto é, o impulso de supressão violenta, inclusive intelectual, de toda forma de alteridade; 2) Mover-se num equilibrio entre adaptação e crítica, isto é, a educação deve capacitar ao indivíduo o estar no mundo concretamente posto e estimular seu inconformismo, sua capacidade de re-criação desse mundo; 3) Orientar-se positivamente pelo ideal de superação da autoinculpável menoridade dos homens, ou seja, pelo propósito de favorecer em cada um a aptidão e a coragem de servir-se do entendimento sem a necessidade da tutela de outrem. Esta projeção de uma geração que supere os entraves para a sua devida emancipação faz do pensamento de Adorno algo a se renovar perenemente através dos anos, enquanto vivenciarmos um mundo capaz de reproduzir algumas intolerâncias e fronteiras descabidas. 


\section{REFERÊNCIAS}

ADORNO. T.W.; HORKHEIMER, M. Dialética do Esclarecimento: fragmentos filosóficos. Trad.: Guido de Almeida. Rio de Janeiro: Jorge Zahar Ed., 1985.

Dialética Negativa. Trad.: José Maria Rispalda. Revisor Jesús Aguirre. Madrid: Taurus, 1975.

Educação e Emancipação. Trad. Wolfgang Leo Maar. Rio de Janeiro: Paz e Terra, 1995a.

Entrevista a revista alemã Der Spiegel. 1969. Lua Nova: Revista de Cultura e Política, São Paulo, n. 60, 2003. Disponível em: <http://www.scielo.br/scielo.php>. Acesso em: 22 nov. 2004.

Mínima Moralia: reflexões a partir da vida danificada. 2. ed. São Paulo: Ática, 1993.

BATISTA, Sueli Soares S. Teoria Critica e teorias educacionais: uma análise do discurso sobre educação. Revista Educação e Sociedade, ano XXI, dez. 2000.

CEPPAS, Felipe. Formação filosófica e crítica: Adorno e o ensino de filosofia em nível introdutório. Tese (Doutorado em Educação) - Departamento de Educação, Pontifícia Universidade Católica do Rio de Janeiro, Rio de Janeiro, 2003.

FREUD, Sigmund. El Malestar en la cultura. Trad. Luis Ballesteros y de Torres. In: Obras Completas, Madrid: Ed. Nueva, 1981. vol. 3 .

GAGNEBIN, Jeanne-Marie. Sete aulas sobre Linguagem, Memória e História. Rio de Janeiro: Imago, 1997.

MATOS, Olgária F. Os arcanos do inteiramente outro. São Paulo: Brasiliense, 1989.

MOREIRA, A.F.B.; SILVA, T.T. (Orgs.). Currículo, cultura e sociedade. 2. ed. São Paulo: Cortez, 1995.

SILVA, Tomaz T. A 'nova' direita e as transformações na pedagogia da política e na política da pedagogia. In: Neoliberalismo, qualidade total e educação. Petrópolis: Vozes, 1995.

TORRES, Carlos Alberto. (Org.). Teoria crítica e sociologia política da educação. Trad.: Maria José do Amaral Ferreira. São Paulo: Cortez; Instituto Paulo Freire, 2003.

WIGGERSHAUS, Rolf. A Escola de Frankfurt: história, desenvolvimento teórico, significação política. Trad. do alemão por Lilyane Deroche-Gurgel; Trad. do francês por Vera de Azambuja Harvey; Revisão técnica por Jorge Coelho Soares. Rio de Janeiro: DIFEL, 2002. 


\section{RESUMO}

O presente ensaio discute a sensação de mal-estar enfrentada pela sociedade contemporâneo, resultante das frustrações de compartilhar uma mentalidade regressiva e pouco ilustrada, no sentido emancipatório. Esse clima cultural geral é descrito por T. W. Adorno como uma regressão no tecido civilizatório e se manifesta aqui e acolá como um sintoma de que nem tudo está tão bem resolvido numa dada sociedade tecnologicamente avançada. Deste modo, o homem contemporâneo tornou-se vítima daquilo que ele mesmo provocou através de sua pretensão em dominar as coisas do mundo; regrediu em sua capacidade de ouvir e olhar a natureza como um todo repleto de mistérios nunca conhecidos plenamente. Diante deste quadro, 0 artigo apresenta as funções imperativas para a construção de uma autonomia democrática por meio de uma educação emancipatória, delineando o projeto educacional adorniano, que diz respeito aos esforços de investimento na formação crítica, que não premie a dor e que esclareça a respeito das possibilidades de que haja outras canalizações para a fúria represada das frustações cotidianas. Com este alerta, Adorno defende o seu principal projeto educaciconal: que Auschwitz não se repita.

Palavras-chave: Teoria Crítica. T. W. Adorno. Educação Emancipatória.

\section{ABSTRACT}

This essay discusses the sense of malaise faced by contemporary society, resulting from the frustrations of sharing a regressively ill-illustrated mentality, in the emancipatory sense. This general cultural climate is described by $\mathrm{T}$. W. Adorno as a regression in the civilizing fabric and is manifested here and there as a symptom that not everything is so well resolved in a given technologically advanced society. In this way, the contemporary man became a victim of what he himself provoked through his pretension to dominate the things of the world; he regressed in his ability to hear and to look at nature as a whole replete with mysteries never fully known. In this context, the article presents the imperative functions for the construction of a democratic autonomy through an emancipatory education, outlining the Adornoian educational project, which concerns investment efforts in critical formation, that does not reward pain and that clarifies the respect for the possibilities of other channels for the fury repressed by everyday frustrations. With this warning, Adorno defends his main educational project: that Auschwitz does not repeat itself.

Keywords: Critical Theory. T. W. Adorno. Emancipatory Education.

\section{RESUMEN}

El presente ensayo discute la sensación de malestar enfrentada por la sociedad contemporánea, resultante de las frustraciones de compartir una mentalidad regresiva y poco ilustrada, en el sentido emancipatorio. Este clima cultural general es descrito por T. W. Adorno como una regresión en el tejido civilizatorio y se manifiesta aquí y acoge como un síntoma de que no todo está tan bien resuelto en una dada sociedad tecnológicamente avanzada. De este modo, el hombre contemporáneo se volvió víctima de lo que él mismo provocó a través de su pretensión en dominar las cosas del mundo; ha regresado en su capacidad de oír y mirar la naturaleza como un todo repleto de misterios nunca conocidos plenamente. En el marco de este cuadro, el artículo presenta las funciones imperativas para la construcción de una autonomía democrática a través de una educación emancipatoria, delineando el proyecto educativo adorniano, que se refiere a los esfuerzos de inversión en la formación crítica, que no premie el dolor y que aclare el respeto de las posibilidades de que haya otras canalizaciones para la furia represada de las frustraciones cotidianas. Con esta alerta, Adorno defiende su principal proyecto educativo: que Auschwitz no se repita.

Palabras clave: Teoría Crítica. T T. Adorno. Educación Emancipatoria.

Submetido em: 06 de janeiro de 2019 Aprovado em: 30 de maio de 2019 